\title{
SNAI1 interacts with HDAC1 to control TGF- $\beta 2$-induced epithelial-mesenchymal transition in human lens epithelial cells
}

\author{
NING GAO*, JINGMING LI*, YAZHOU QIN, YINGNA WANG, QIANYANG KANG and CHENG PEI \\ Department of Ophthalmology, First Affiliated Hospital of Xi'an Jiaotong University, Xi'an, Shaanxi 710061, P.R. China
}

Received February 3, 2019; Accepted September 3, 2019

DOI: $10.3892 / \mathrm{ijmm} .2019 .4405$

\begin{abstract}
The opacity of the lens capsule after cataract surgery is caused by epithelial-to-mesenchymal transition (EMT) of lens epithelial cells. Snail family transcriptional repressor 1 (SNAI1) is a transcriptional repressor that recruits multiple chromatin enzymes including lysine-specific histone demethylase $1 \mathrm{~A}$, histone deacetylase (HDAC) 1/2, polycomb repressive complex 2 , euchromatic histone lysine methyltransferase 2 and suppressor of variegation 3-9 homolog 1 to the E-cadherin promoter, thereby suppressing E-cadherin expression. However, the functional relationship between SNAI1 and HDAC in the induction of EMT in human lens epithelial cells (HLECs) is still unclear. Therefore, the objective of the present study was to explore the possible functional relationship between SNAI1 and HDAC1 in the induction of EMT in HLECs. In the present study, SNAI1 was found to be increased in HLECs during transforming growth factor- $\beta 2$ (TGF- $\beta 2$ )-induced EMT. Knockdown of SNAI1 by siRNA reversed TGF- $\beta 2$-induced downregulation of E-cadherin and upregulation of $\alpha$-Smooth Muscle Actin. Furthermore, SNAI1 was found to be associated with HDAC1 in the E-cadherin promoter in TGF- $\beta 2$-treated HLECs. Inhibition of HDAC by trichostatin A and suberoylanilide hydroxamic acid could prevent TGF- $\beta 2$-induced EMT in HLECs. Collectively, SNAI1 interacted with HDAC1 to repress E-cadherin in the TGF- $\beta 2$-induced EMT in HLECs, suggesting that HDAC inhibitors may have potential therapeutic value for the prevention of EMT in HLECs.
\end{abstract}

\section{Introduction}

Posterior capsule opacification (PCO) is a common postoperative complication of phacoemulsification or extracapsular

Correspondence to: Professor Cheng Pei, Department of Ophthalmology, First Affiliated Hospital of Xi'an Jiaotong University, 277 West Yanta Road, Xi'an, Shaanxi 710061, P.R. China E-mail: peich71@163.com

*Contributed equally

Key words: human lens epithelial cells, transforming growth factor- $\beta 2$, histone deacetylase, snail family transcriptional repressor 1 , epithelial to mesenchymal transition cataract extraction (1), which are mainly caused by the proliferation and migration of residual lens epithelial cells (LECs) in the anterior and equator lens capsule after cataract surgery (2,3). In total, $20-40 \%$ of adult and $100 \%$ of pediatric patients suffer from visual loss due to PCO after cataract surgery (1). At present, epithelial-mesenchymal transition (EMT) of the postoperative residual LECs is believed to be the primary cause underlying PCO pathogenesis $(4,5)$. During the process of EMT, epithelial cells lose cell polarity and cell-cell adhesion, gain migratory and invasive properties, and acquired characteristics of mesenchymal stem cells (1). Due to hyperplasia, migration and transdifferentiation of LECs, the lens posterior capsule may exhibit thickening, opacification and clouding (1). Several signaling pathways may be involved in EMT (6). The residual LECs after cataract surgery could release autocrine molecules such as transforming growth factor- $\beta 2$ (TGF- $\beta 2$ ), which is secreted into the aqueous humor in the capsular bag $(7,8)$. Additionally, in our previous studies, TGF- $\beta 2$ was found to be able to induce EMT in human LECs $(9,10)$.

EMT is characterized by the loss of epithelial markers, such as E-cadherin, and the acquisition of mesenchymal markers, such as $\alpha$-Smooth Muscle Actin ( $\alpha$-SMA) and fibronectin. Several transcription factors, such as snail family transcriptional repressor 1 (SNAI1), Twist and zinc finger E-box binding homeobox 1, are involved in EMT by repressing E-cadherin transcription in vitro and in vivo (11). Previous studies suggested that the transcription factor SNAI1 is able to regulate the EMT process of some cells such as alveolar epithelial cells (12). In addition, SNAI1 regulated EMT in a variety of other physiological and pathological processes, such as embryonic development, tissue fibrosis and metastasis of malignant tumors (13). SNAI1 recruits multiple chromatin enzymes including lysine-specific demethylase 1A (LSD1), histone deacetylase (HDAC) $1 / 2$, polycomb repressive complex 2 (PRC2), euchromatic histone lysine methyltransferase 2 (EHMT2) and suppressor of variegation 3-9 homolog 1 (SUV39H1) to the E-cadherin promoter, thereby suppressing E-cadherin expression in cancers cells (14). HDACs are enzymes that remove the acetyl groups from histones and increase the affinity between DNA and histones (2). HDAC activity can be inhibited by inhibitors such as trichostatin A (TSA) and suberoylanilide hydroxamic acid (SAHA) (15). HDAC1 has a zinc-dependent active site and can be recruited by various transcription factors, such as SNAI1, which belongs 
to the zinc finger transcription factor family (3). However, to the best of our knowledge, the possible functional relationship between SNAI1 and HDAC1 in the induction of EMT in HLECs has not been yet reported.

Therefore, the aim of this study was to determine whether the transcription factor SNAI1 is involved in the EMT process of HLECs induced by TGF- $\beta 2$, and to investigate the potential functional relationship between SNAI1 and HDAC1 during that process.

\section{Materials and methods}

Cell culture. Immortalized HLEB-3 cells were obtained from The American Type Culture Collection (ATCC) and cultured in Eagle's Minimal Essential Medium (EMEM; ATCC) supplemented with 10\% FBS (Gibco; Thermo Fisher Scientific, Inc.) in a humidified atmosphere containing 5\% $\mathrm{CO}_{2}$ at $37^{\circ} \mathrm{C}$. HLEB-3 cells were treated with various doses of TGF- $\beta 2(1 \mu \mathrm{g} / \mathrm{ml}$ dissolved in PBS; PeproTech, Inc.) for the indicated time with or without TSA (Sigma-Aldrich; Merck $\mathrm{KGaA}$ ) or SAHA (Sigma-Aldrich; Merck KGaA), which are class I and II HDAC inhibitors. The specific small interfering RNA (siRNA) for SNAI1 (cat. no. sc-38398) and control siRNA (cat. no. sc-37007) were purchased from Santa Cruz Biotechnology, Inc. The HLEB-3 cells, seeded on six-well plate, were transfected with $5 \mu$ l SNAI1 siRNA or control siRNA at a concentration of $10 \mu \mathrm{M}$ using Lipofectamine RNAiMax (Thermo Fisher Scientific, Inc.) for $48 \mathrm{~h}$ prior to further experimentation, according to the manufacturer's protocol.

Immunocytochemistry. HLEB-3 cells were cultured and treated with $1 \mathrm{ng} / \mathrm{ml}$ TGF- $\beta 2$. Cells were fixed using $4 \%$ formaldehyde at room temperature for $10 \mathrm{~min}$ and then permeabilized with $0.5 \%$ Triton X-100 in PBS at room temperature for $5 \mathrm{~min}$. After blocking with $1 \%$ BSA in PBS at room temperature for $1 \mathrm{~h}$, HLEB-3 cells were incubated with mouse anti-SNAI1 antibodies (cat. no. sc-271977; 1:200; Santa Cruz Biotechnology, Inc.) at $4^{\circ} \mathrm{C}$ overnight. Subsequently, samples were incubated with Alexa Fluor 488-conjugated donkey anti-mouse antibody (cat. no. A21202; 1:1,000; Thermo Fisher Scientific, Inc.) at room temperature for $1 \mathrm{~h}$. The nuclei were counterstained with VECTASHIELD mounting medium containing DAPI (Vector Laboratories). The slides were observed using a fluorescent microscope (Carl Zeiss AG; magnification, x400) and representative images were obtained.

Reverse transcription-quantitative PCR (RT-qPCR). Total RNA was extracted from cultured HLEB-3 cells using the RNeasy Mini kit (Qiagen, Inc.) following the manufacturer's protocol. mRNA was reverse transcribed to cDNA using the Maxima First Strand cDNA Synthesis kit (Thermo Fisher Scientific, Inc.). The reverse transcription reaction was incubated for $10 \mathrm{~min}$ at $25^{\circ} \mathrm{C}$, for $15 \mathrm{~min}$ at $50^{\circ} \mathrm{C}$ and for $5 \mathrm{~min}$ at $85^{\circ} \mathrm{C}$. RT-qPCR was conducted using the Power SYBR Green (Takara Biotechnology, Co., Ltd.) according to the manufacturer's protocol using the Applied Biosystems 7500 Fast Real-Time PCR System (Thermo Fisher Scientific, Inc.) under the following condition: Initial denaturation at $95^{\circ} \mathrm{C}$ for $5 \mathrm{~min}$, followed by 40 cycles of $95^{\circ} \mathrm{C}$ for $30 \mathrm{sec}, 60^{\circ} \mathrm{C}$ for $1 \mathrm{~min}, 95^{\circ} \mathrm{C}$ for $1 \mathrm{~min}$ and $60^{\circ} \mathrm{C}$ for $1 \mathrm{~min}$. Data were analyzed using the $2^{-\Delta \Delta \mathrm{Cq}}$ method (16). The primer sequence for RT-qPCR were as follows: E-cadherin forward, 5'-AGT GACTGATGCTGATGCCC-3' and reverse, 5'-CTGCATCTT GCCAGGTCCTT-3'; fibronectin forward, 5'-TATTGAAGG CTTGCAGCCCA-3 and reverse, 5'-CACCATCAGGTGCAG GGAAT-3'; $\alpha$-SMA forward, 5'-CAGGCTCAAGTCTGTCTT TGC-3' and reverse, 5'-CCGCCTGGATAGCCACATAC-3'; $\beta$-actin forward, 5'-AAACTGGAACGGTGAAGGTG-3' and reverse, 5'-GTGGCTTTTAGGATGGCAAG-3'. $\beta$-actin was used as the reference gene.

Western-blot analysis. HLEB-3 cells were lysed in RIPA buffer $(50 \mathrm{mM}$ Tris, $\mathrm{pH} 7.4,150 \mathrm{mM} \mathrm{NaCl}, 1 \% \mathrm{NP}-40$, $0.5 \%$ sodium deoxycholate, $0.1 \%$ SDS; Beyotime Institute of Biotechnology) containing $1 \%$ protease inhibitors (PhosStop phosphatase inhibitor cocktail tablet; Roche Diagnostics) at $4^{\circ} \mathrm{C}$ for $30 \mathrm{~min}$. The cell lysates were harvested and centrifuged at $14,000 \times \mathrm{g}$ at $4^{\circ} \mathrm{C}$ for $10 \mathrm{~min}$. Subsequently, the supernatants were collected. The protein concentration was quantified using a Pierce bicinchoninic acid Protein Assay kit (Thermo Fisher Scientific, Inc.). After denaturing the samples with Laemmli buffer (Bio-Rad Laboratories, Inc.) at $95^{\circ} \mathrm{C}$ for $5 \mathrm{~min}, 20 \mu \mathrm{g}$ of total protein was separated by 10\% SDS-PAGE (Beyotime Institute of Biotechnology), and then transferred onto a PVDF membrane (EMD Millipore). After blocking with 5\% non-fat dry milk in TBST (TBS + $0.1 \%$ Tween-20) for $1 \mathrm{~h}$ at room temperature, the membranes were washed with TBST three times. The membranes were subsequently incubated overnight at $4^{\circ} \mathrm{C}$ with the following primary antibodies: Rabbit anti-fibronectin (cat. no. sc-9068, Santa-Cruz Biotechnology, Inc.), mouse anti- $\alpha-S M A$ (cat. no. A2547, Sigma-Aldrich; Merck KGaA), rabbit anti-E-cadherin (cat. no. 3195; Cell Signaling Technology, Inc.), mouse anti-SNAI1 (cat. no. sc-271977; Cell Signaling Technology, Inc.) and mouse anti-GAPDH (cat. no. ab9482; Abcam, Inc.) or mouse anti- $\beta$-actin (cat. no. A5441; Sigma-Aldrich; Merck KGaA). The membranes were washed in TBST and then incubated for $1 \mathrm{~h}$ at room temperature with horseradish peroxidase-conjugated goat anti-mouse (1:2,000; cat. no. BA1051; Wuhan Boster Biological Technology Co., Ltd.) and goat anti-rabbit secondary antibodies (1:2,000; cat. no. BA1054; Boster Biological Technology Co., Ltd.). The specific bands were detected using an ECL reagent (Applygen Technologies, Inc.) and BioMax film (Kodak). The bands were analyzed using GEL-PRO Analyzer software (version 4.0; Media Cybernetics, Inc.).

Immunoprecipitation. HLEB-3 cells were lysed for $60 \mathrm{~min}$ at $4^{\circ} \mathrm{C}$ in extraction buffer containing $50 \mathrm{mmol} / 1$ Tris $-\mathrm{Cl}$ (pH 7.5), $100 \mathrm{mmol} / \mathrm{l} \mathrm{NaCl}, 1 \%$ Triton X-100, $1 \mathrm{mmol} / \mathrm{l}$ DTT, $1 \mathrm{mmol} / 1$ EDTA, $1 \mathrm{mmol} / 1$ EGTA, $2 \mathrm{mmol} / 1 \mathrm{Na}_{3} \mathrm{VO}_{4}$, $50 \mathrm{mmol} / 1 \beta$-glycerophosphate and a protease inhibitor (Roche Diagnostics). The cell lysates were pre-washed with protein A/G-agarose beads (Cell Signaling Technology, Inc.) and pelleted by centrifugation at $1,000 \mathrm{x}$ for $5 \mathrm{~min}$ at $4^{\circ} \mathrm{C}$. The supernatant was collected and further incubated with control IgG or mouse anti-SNAI1 (1:100; cat. no. ab78105; Abcam, Inc.) or rabbit anti-HDAC1 (1:100; cat. no. ab7028; Abcam, Inc.) antibody conjugated with protein $\mathrm{A} / \mathrm{G}$-agarose beads 
at $4^{\circ} \mathrm{C}$ overnight. The beads were washed twice with extraction buffer and twice with extraction buffer with $0.5 \mathrm{~mol} / \mathrm{l}$ $\mathrm{LiCl}$. Proteins were eluted directly in non-reducing buffer for western-blot analysis.

Chromatin immunoprecipitation (ChIP). The ChIP assay was performed using a ChIP kit (cat. no. ab500; Abcam, Inc.) according to the manufacturer's protocol. Briefly, $1 \times 10^{7}$ HLEB-3 cells were crosslinked with $1 \%$ formaldehyde at room temperature for $10 \mathrm{~min}$, lysed with ChIP lysis buffer on ice for $10 \mathrm{~min}$ and sonicated to produce chromatin fragments. The precipitation was performed with polyclonal antibodies against HDAC1 (1:100; cat. no. ab7028; Abcam, Inc.) at $4^{\circ} \mathrm{C}$ for 1 h. The rabbit immunoglobumin G (1:100; cat. no. ab172730; Abcam Inc.) was used as negative control. The precipitation of the E-cadherin promoter was determined by PCR with Taq DNA polymerase (Takara Biotechnology, Co., Ltd.) using primer spanning from nucleotide -680 to -541 of the E-cadherin sequence under the following conditions: Initial denaturation at $95^{\circ} \mathrm{C}$ for $5 \mathrm{~min}$, followed by 35 cycles of $95^{\circ} \mathrm{C}$ for $30 \mathrm{sec}$, $62^{\circ} \mathrm{C}$ for $30 \mathrm{sec}$, and $72^{\circ} \mathrm{C}$ for $30 \mathrm{sec}$, with a final extension at $72^{\circ} \mathrm{C}$ for $5 \mathrm{~min}$. The amplification primers of E-cadherin promoter were as follows: Forward: 5'-GTCACCGCGTCT ATGCGAGGCCG-3' and reverse: 5'-GCGTGGCTGCAG CCAGGTG-3'. The PCR product was detected using a $1.5 \%$ agarose gel and visualized with ethidium bromide.

Statistical analysis. Data were presented as the mean \pm SEM and statistical analysis were performed with SPSS 17.0 software (SPSS, Inc.). Each experiment was independently repeated at least three times. One way ANOVA was used to compare three or more groups, followed by Bonferroni's post hoc test. Student's t-test was used to analyze the differences between two independent groups. $\mathrm{P}<0.05$ was considered to indicate a statistically significant difference.

\section{Results}

TGF- $\beta 2$ promotes EMT markers in HLECs. To examine whether TGF- $\beta 2$ induced EMT in HLECs, the mRNA and protein expression levels of various molecules, including E-cadherin, fibronectin and $\alpha$-SMA, were examined. After treatment with TGF- $\beta 2(10 \mathrm{ng} / \mathrm{ml})$, there was a slight reduction of E-cadherin expression at $12 \mathrm{~h}$, followed by a remarkable decrease in its expression at 24 and $48 \mathrm{~h}$ (Fig. 1A). Furthermore, TGF- $\beta 2(10 \mathrm{ng} / \mathrm{ml})$ induced a significant upregulation of fibronectin (Fig. 1B) and $\alpha$-SMA (Fig. 1C) in HLEB-3 cells in a time-dependent manner. Consistently, the protein level of E-cadherin was significantly downregulated by TGF- $\beta 2$ after $24 \mathrm{~h}$ (Fig. 1D and E). Furthermore, the expression levels of fibronectin and $\alpha$-SMA, two major fibrotic markers, were upregulated by TGF- $\beta 2$ treatment (Fig. 1D and E). Treatment with different doses of TGF- $\beta 2$ resulted in a concentration-dependent decrease in E-cadherin expression but a concentration-dependent increase in fibronectin and $\alpha$-SMA expression in HLEB-3 cells at both mRNA (Fig. 1F-H) and protein level (Fig. 1I and J). Collectively, the present results suggested that TGF- $\beta 2$ upregulated EMT markers in HLEB3 cells by reducing E-cadherin expression and increasing fibronectin and $\alpha$-SMA expression.
Involvement of SNAII in TGF- $\beta 2$-induced E-cadherin downregulation in HLEB-3. SNAI1 is an important transcription factor in EMT (17). Therefore, the role of SNAI1 in TGF- $\beta 2$-induced EMT was examined by immunostaining and western-blot analysis. As shown in Fig. 2A, SNAI1 was weakly expressed and mainly distributed in the nucleus of quiescent HLEB3 cells. Consistently, nuclear SNAI1 expression was markedly increased in HLEB-3 cells after TGF- $\beta 2$-treatment. Moreover, SNAI1 expression was dramatically increased in TGF- $\beta 2$-treated HLEB-3 cells in both dose- and time-dependent manner (Fig. 2B-E). Next, HLEB-3 cells were transfected with specific SNAI1-siRNA and control siRNA. The expression level of SNAI1 was decreased following SNAI1-siRNA transfection (Fig. S1). The western-blot analysis demonstrated that SNAI1-siRNA significantly reduced TGF- $\beta 2$-induced SNAI1 expression (Fig. 3A). Moreover, knockdown of SNAI1 by siRNA dramatically reversed TGF- $\beta 2$-associated downregulation of E-cadherin and upregulation of $\alpha$-SMA (Fig. 3B), which suggested a causal role of SNAI1 in regulating EMT markers.

SNAII is associated with HDACl in the TGF- $\beta 2$-mediated $E$-cadherin repression. In the present study, it was investigated whether SNAI1 was directly associated with HDAC1 at the E-cadherin promoter by immunoprecipitation assay and ChIP. After immunoprecipitation with SNAI1 antibody, SNAI1 was found to be associated with HDAC1 (Fig. 4A). Consistently, after immunoprecipitation with HDAC1 antibody, HDAC1 was found to interact with SNAI1. Intriguingly, by using ChIP assay, a direct interaction between HDAC1 and E-cadherin promoter was confirmed (Fig. 4B). The present data suggested that the association of SNAI1 and HDAC1 is involved in transcriptional inhibition E-cadherin induced by TGF- $\beta 2$.

HDAC inhibition prevents TGF- $\beta 2$-induced E-cadherin downregulation in HLEB-3 cells. The effect of HDAC inhibition on the TGF- $\beta 2$-induced decrease of E-cadherin and increase of $\alpha$-SMA was then examined. TSA and SAHA were used as HDAC inhibitors. The present results suggested that SAHA prevented TGF- $\beta 2$ induced $\alpha$-SMA upregulation and reversed E-cadherin downregulation (Fig. 5A, C and D). Furthermore, TGF- $\beta 2$-induced $\alpha$-SMA upregulation and E-cadherin downregulation were also attenuated by TSA, another HDAC inhibitor (Fig. 5B, E and F). Collectively, inhibition of HDAC activity could attenuate the TGF- $\beta 2$-induced increase of EMT markers in HLEB3 cells.

\section{Discussion}

Accumulating evidence demonstrated that the underlying mechanism of PCO is a wound-healing process in response to postoperative residual LECs initiated by surgical stress $(4,18)$. Some of these cells undergo EMT, which includes cell proliferation and migration. These cells migrate along the lens capsule into the visual axis with ectopic proliferation and loss of epithelial phenotype (1). Therefore, they gain a myofibroblast-like phenotype (1). On one hand, downregulation of E-cadherin expression can reduce intercellular adhesion (19). On the other hand, 
A
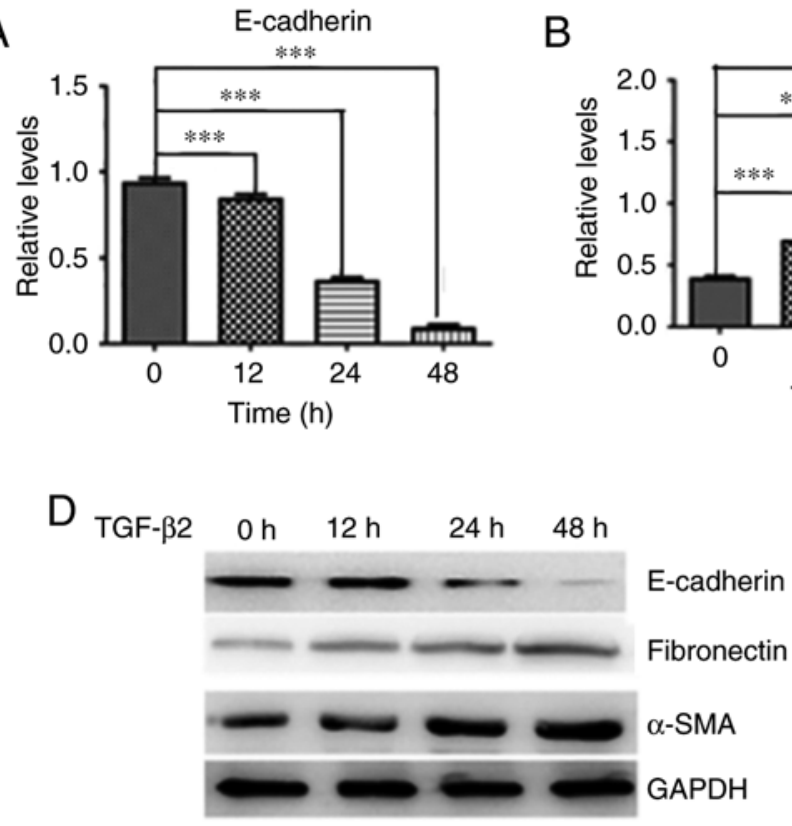

B

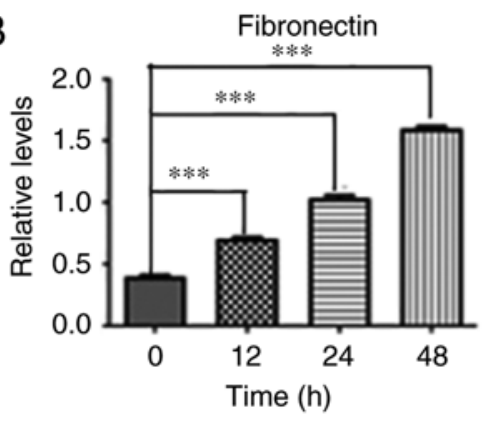

C

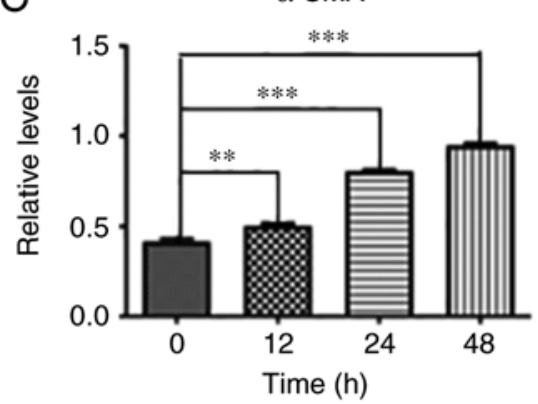

$\mathrm{F}$

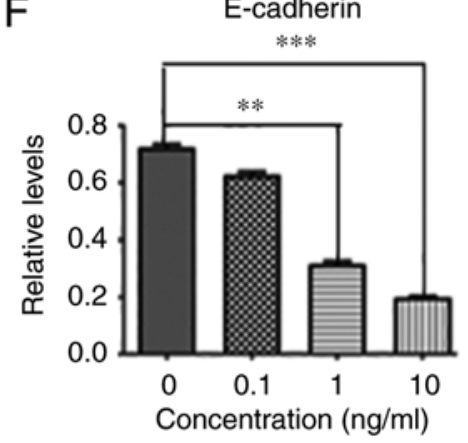

G

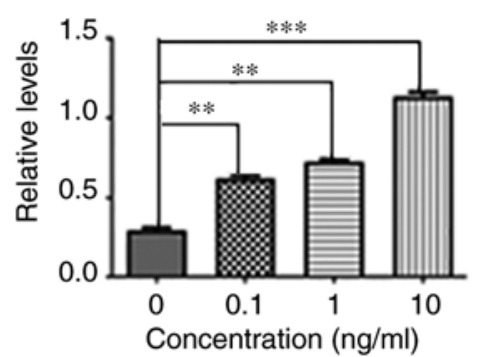

$\mathrm{H}$

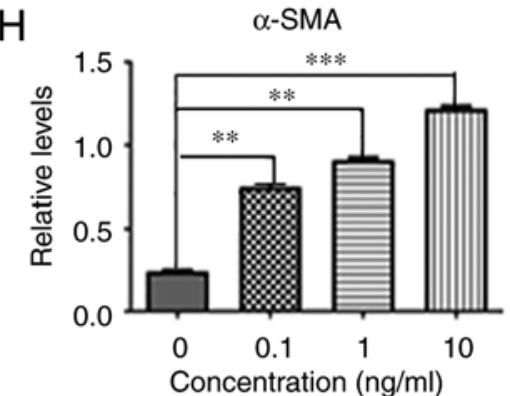

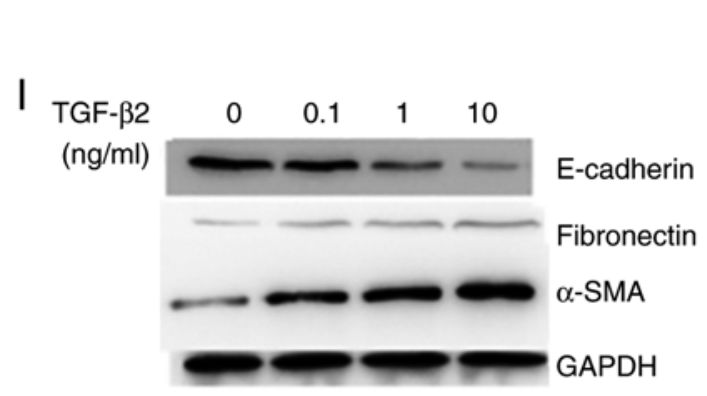

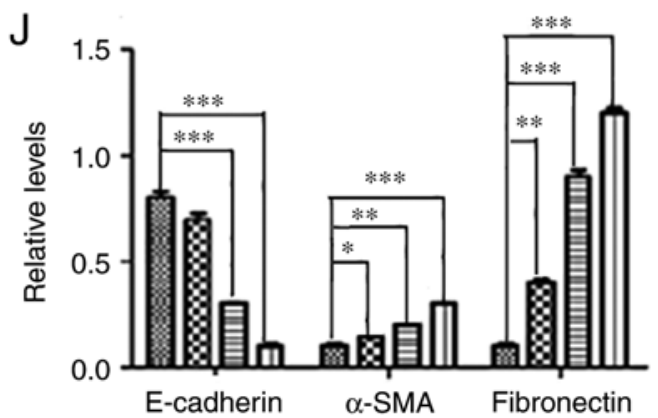

Figure 1. TGF- $\beta 2$ induces the expression of EMT markers in HLEB- 3 cells. HLEB- 3 cells were treated with TGF- $\beta 2$ at $10 \mathrm{ng} / \mathrm{ml}$ for 12,24 and $48 \mathrm{~h}$, and the mRNA levels of (A) E-cadherin, (B) fibronectin and (C) $\alpha$-SMA were detected by RT-qPCR. (D) Western blot analysis and (E) quantification of the protein expression levels of E-cadherin, fibronectin and $\alpha$-SMA. HLEB-3 cells were treated with TGF- $\beta 2$ at various concentrations $(0.1,1$ and $10 \mathrm{ng} / \mathrm{ml})$ for $48 \mathrm{~h}$, and the mRNA levels of (F) E-cadherin, $(\mathrm{G})$ fibronectin and $(\mathrm{H}) \alpha$-SMA were detected by RT-qPCR. (I) Western blot analysis and (J) quantification of the protein expression levels of E-cadherin, fibronectin and $\alpha$-SMA. $n=3$. ${ }^{*} \mathrm{P}<0.05,{ }^{* *} \mathrm{P}<0.01,{ }^{* * * *} \mathrm{P}<0.001$. RT-qPCR, reverse transcription-quantitative PCR; SMA, smooth muscle actin; TGF, transforming growth factor.

upregulation of $\alpha$-SMA expression contributes to tissue fibrosis (19). Additionally, cells produce more extracellular matrix containing glycoprotein, fibrin and various types of collagen fibers (10). Cellular fibronectin is incorporated into the fibrillar matrix of the cell surface, and its level can be measured by examining the protein expression and mRNA levels in cellular extracts $(20,21)$. Therefore, the deposition of these molecules on the surface of the posterior capsule may lead to impaired vision (1).
During the process of EMT, epithelial cells lose cell polarity and adhesion, gain migratory and invasive properties, and acquire a mesenchymal stem cell-like phenotype (22). Loss of the adhesion factor E-cadherin is one of the most important events underlying EMT (22). Several signaling pathways, including TGF- $\beta 2$, fibroblast growth factor, epidermal growth factor, hepatocyte growth factor, Wnt/ $\beta$-catenin and Notch pathways, may be involved in EMT. Tamiya et al (23) found that TGF- $\beta 2$ can induce EMT in retinal pigment epithe- 


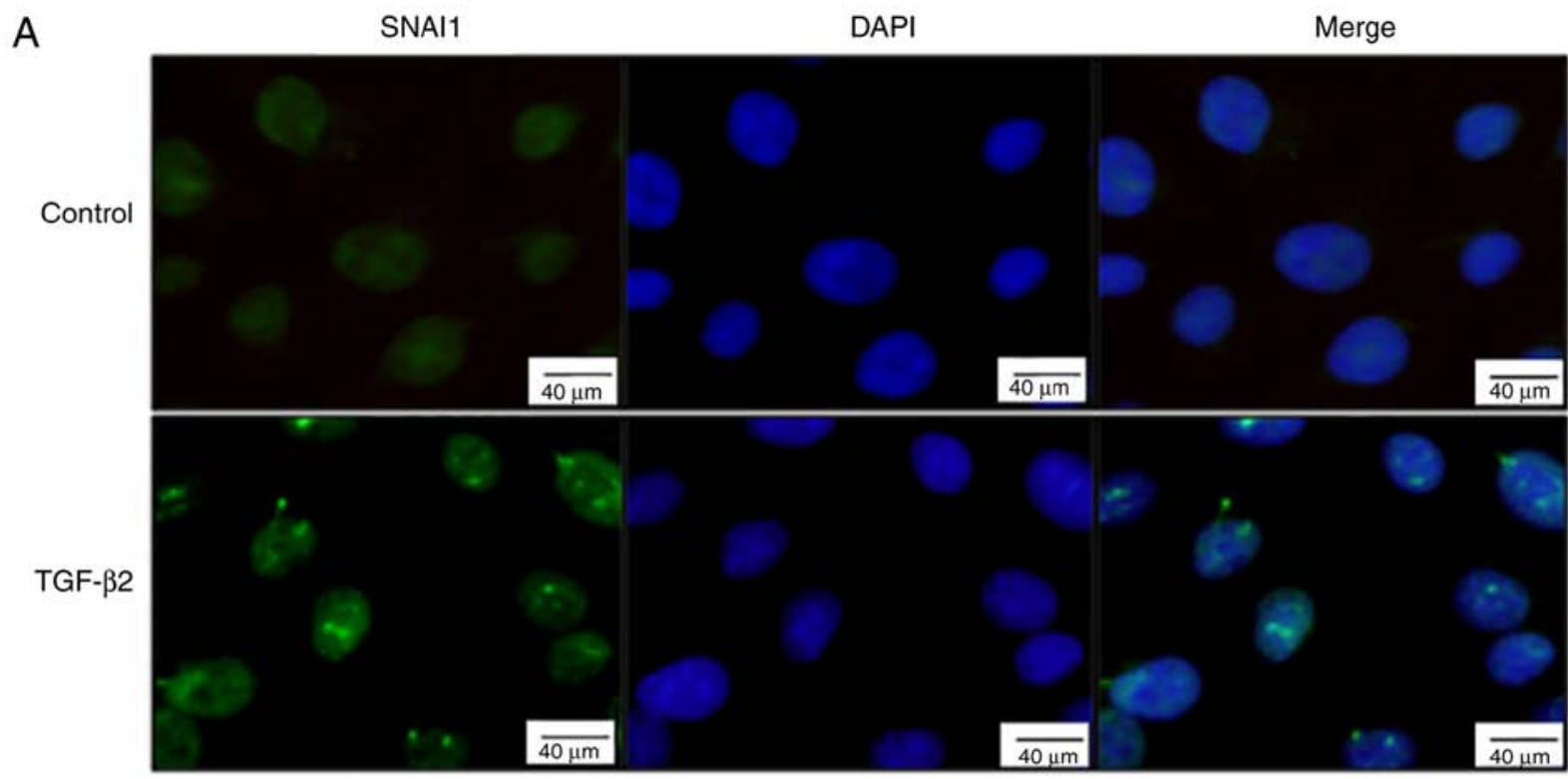

B $\begin{array}{r}\text { TGF- } \beta 2 \\ (\mathrm{ng} / \mathrm{ml})\end{array}$

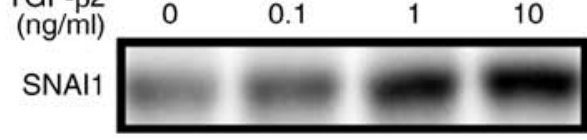
$\beta$-actin

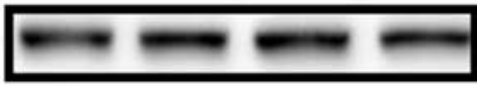

D

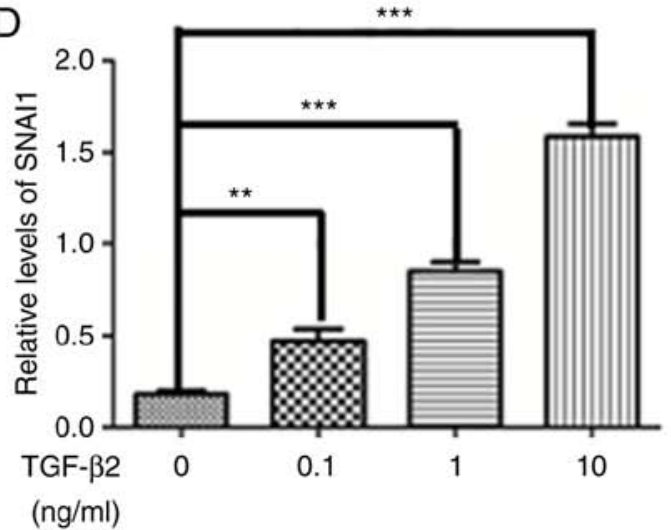

C TGF- $\beta 2$

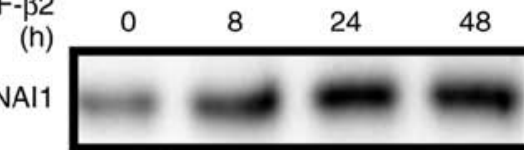

$\beta$-actin

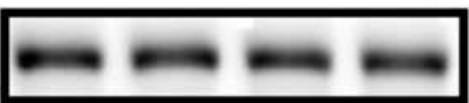

E

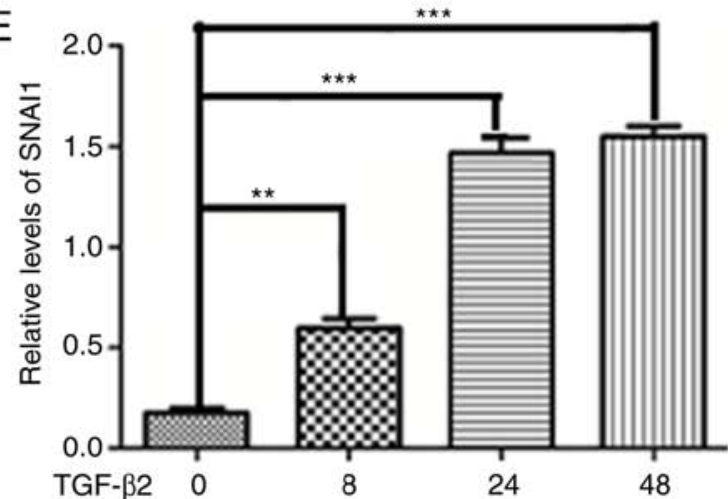

(h)

Figure 2. TGF- $\beta 2$ upregulates and activates SNAI1 in HLEB-3 cells. (A) TGF- $\beta 2$ induced the translocation of SNAI1 from the cytosol into the nucleus. Cellular distribution of SNAI1 was examined by immunocytochemistry. SNAI1 was upregulated by TGF- $\beta 2$ in a (B) dose- and (C) time-dependent manner, as assessed by western blotting. Quantification of the protein expression levels of SNAI with (D) various concentrations of TGF- $\beta 2$ and (E) over time. $n=3$. ${ }^{* *} \mathrm{P}<0.01,{ }^{* * * *} \mathrm{P}<0.001$. TGF, transforming growth factor; SNAI1, Snail family transcriptional repressor 1 .

lial cells, participating in proliferative vitreous retinal disease. Dwivedi et al (24) used TGF- $\beta 2$ to induce EMT in lens epithelial cells of rats, resulting in the upregulation of matrix metalloproteinases and the formation of cloudy lens. The residual epithelial cells after cataract surgery can sense signal via autocrine TGF- $\beta 2$, which is secreted into the aqueous humor in the capsular bag (25). Our previous studies have also shown that TGF- $\beta 2$ plays an important role in inducing EMT, migration and proliferation of LECs (9).

TGF- $\beta 2$ could induce EMT in HLECs (26). The signaling pathways that are activated in response to TGF- $\beta 2$ and lead to EMT have primarily been conducted in vitro using NMuMG,
MDCK and HaCaT cell lines (27-30). In the present study, EMT in HLEB-3 cells was activated when cells were incubated with TGF- $\beta 2$, providing new insight for further exploring the potential functional relationship between SNAI1 and HDAC1 in the pathogenesis of $\mathrm{PCO}$ and its underlying mechanisms.

A recent study suggested that proteins of the SNAI1 family are important regulatory factors in the process of EMT in a variety of cell types (17). The transcription factors belonging to the SNAI family are highly homologous at the N-terminal region, but variable at the $\mathrm{C}$-terminal region, which is formed by a variable number of zinc finger structures (31). SNAI proteins are involved in multiple steps in the process of EMT induced 
A

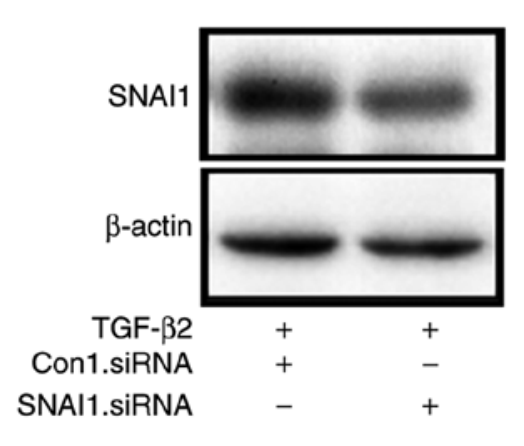

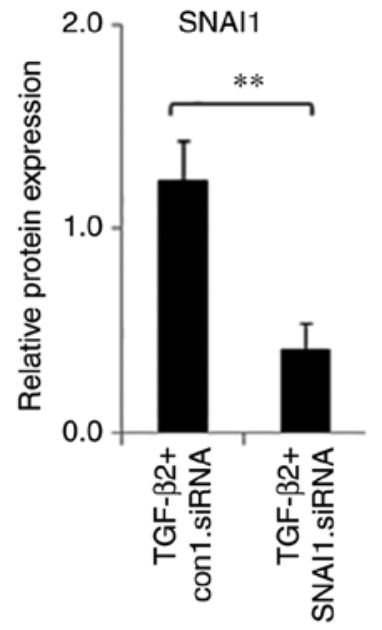
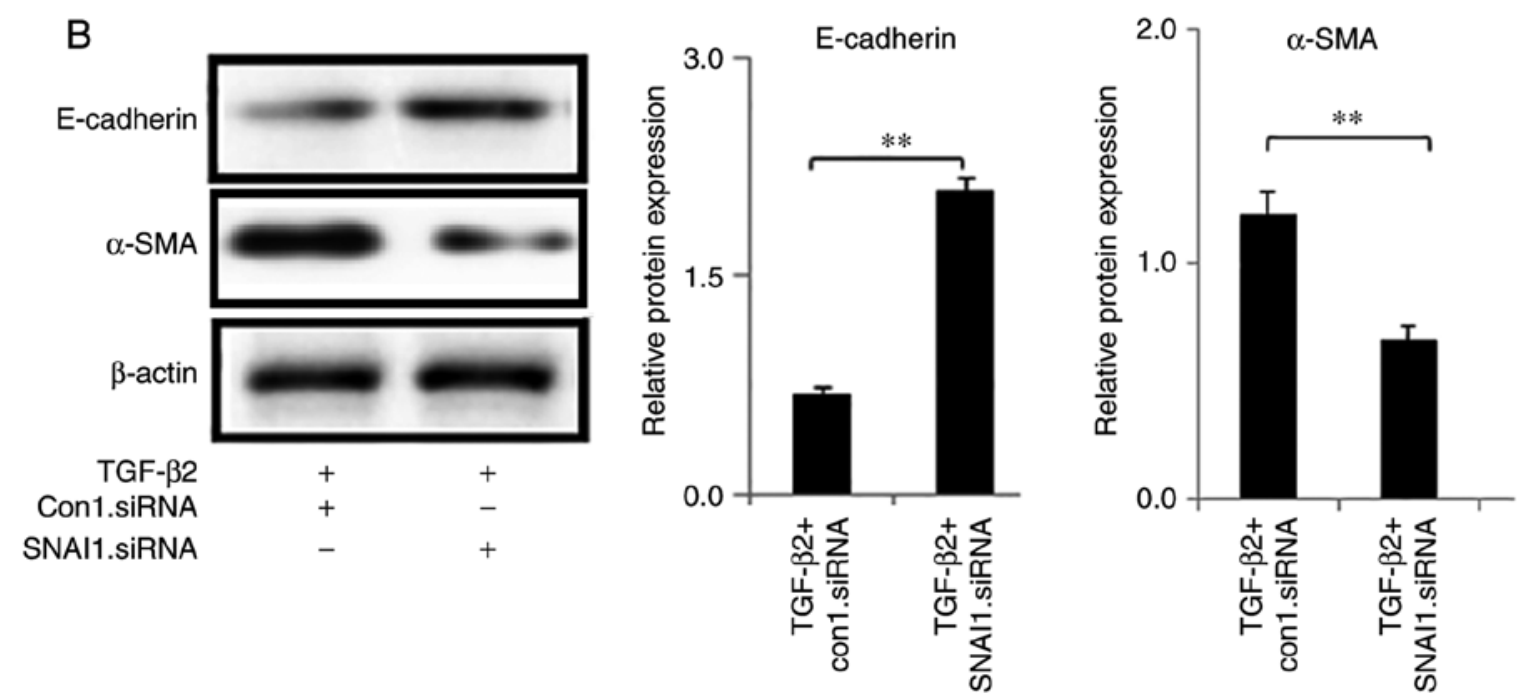

Figure 3. Knockdown of SNAI1 reverses TGF- $\beta 2$-induced downregulation of E-cadherin and upregulation of $\alpha$-SMA. (A) Transfection with SNAI1 siRNA inhibited TGF- $\beta 2$-induced SNAI1 expression. (B) Knockdown of SNAI1 by siRNA ameliorated TGF- $\beta 2$-induced reduction of E-cadherin and increase of $\alpha$-SMA. $\mathrm{n}=3 .{ }^{* *} \mathrm{P}<0.01,{ }^{* * *} \mathrm{P}<0.001$. TGF, transforming growth factor; SNAI1, Snail family transcriptional repressor 1; siRNA, small interfering RNA; Con, control.

by TGF- $\beta 2$, causing tissue or organ fibrosis (32). Furthermore, TGF- $\beta 2$ induces SNAI1 expression during skin (33), palate (34) and heart development (35), as well as in mesothelial cells during pathological fibrosis (36). SNAI1 can bind to the E-boxes of human E-cadherin promoter and repress its transcription, thus reducing cell adhesion (37). The present results identified that TGF- $\beta 2$ induces the increased expression of $\alpha$-SMA, fibronectin and decreased the expression of E-cadherin in HLECs in a time- and dose-dependent manner. Moreover, the expression of SNAI1 was increased as a result of the TGF- $\beta 2$ treatment. HDAC is found primarily in the nucleus (38). HDAC removes the acetyl groups from histones, promoting a high-affinity interaction between histones and DNA. The interaction between DNA and histones can modify the DNA structure, which makes DNA less accessible and thus prevents its transcription (38). The abnormal expression of HDAC1 is involved in many pathological processes. Zupkovitz et al (39) found that a specific subset of genes was dysregulated in the absence of HDAC1 in mice. SNAI1 is a transcriptional repressor that recruits multiple chromatin enzymes including HDAC1/2, LSD1, PRC2, EHMT2 and SUV39H1 to the E-cadherin promoter, thereby suppressing E-cadherin expression during cancers cell metastasis (14,40-43).
In the present study, SNAI1 was found to directly interact with HDAC1 at E-cadherin promoter by immunoprecipitation assay and ChIP. The present results suggested that SNAI1 and HDAC1 may be involved in E-cadherin transcriptional regulation.

HDAC inhibitors such as SAHA and TSA have been used for $\sim 10$ years to treat neurological disorders (44). These inhibitors were being studied as a novel therapy for neurodegenerative disorders (45). A previous study aimed to develop novel HDAC inhibitors to treat cancer, since old HDAC inhibitors have been shown to be ineffective (46). Vorinostat and romidepsin, which belongs to the SAHA family, were approved for the treatment of cutaneous manifestations in patients with cutaneous $\mathrm{T}$ cell lymphoma $(47,48)$. Isoform-selective HDAC inhibitors, which can facilitate the investigation of the specific roles of individual HDAC isoforms, have been developed (49). SNAI1 requires HDAC1 to repress E-cadherin promoter, and treatment with TSA can block the repressive effect of SNAI1. The present study suggested that treatment with HDAC inhibitors, such as SAHA and TSA, completely abrogated upregulation of $\alpha$-SMA and downregulation of E-cadherin, indicating that the HDAC inhibitors can significantly attenuate TGF- $\beta 2$-induced EMT in HLEB-3 cells. 
A
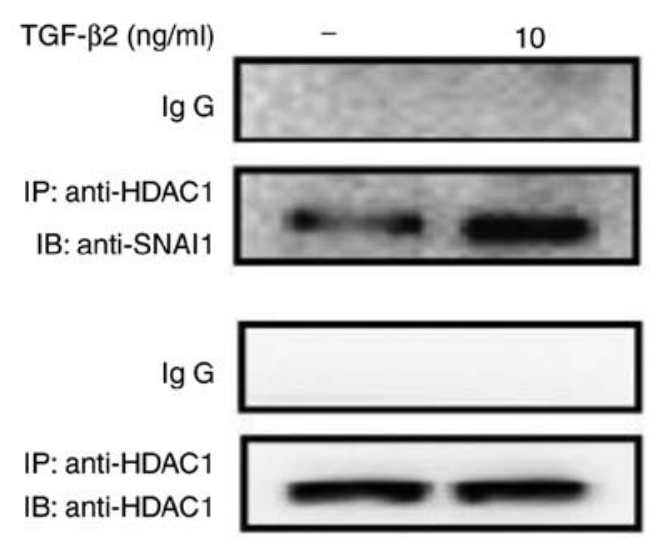

WCL: anti-SNAI 1

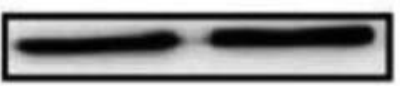

TGF- $\beta 2$ (ng/ml)

$$
\text { Ig } G
$$

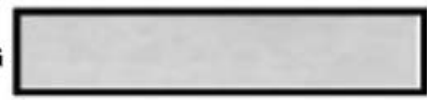

IP: anti-SNAI1

IB: anti-HDAC1

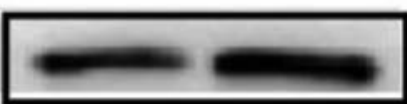

$\lg G$

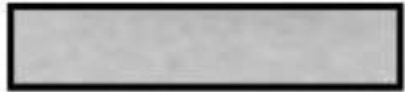

IP: anti-SNAI1

IB: anti-SNAI1

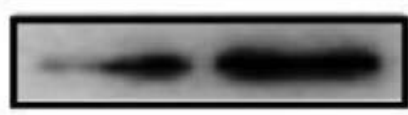

WCL: anti-HDAC1

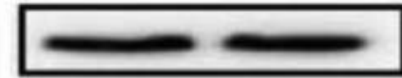

B

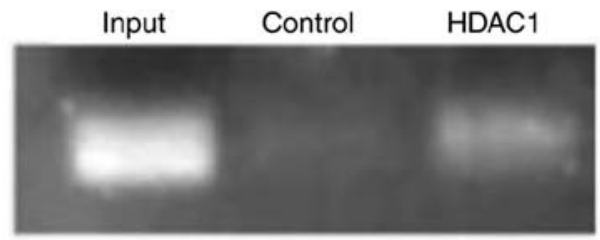

Figure 4. SNAI1 regulates E-cadherin and interacts with HDAC1 at the E-cadherin promoter. (A) SNAI1 and HDAC1 were immunoprecipitated from HLEB-3 cells, and the interaction between HDAC1 and SNAI1 was examined by western-blot analysis. (B) PCR products of the E-cadherin promoter after ChIP assay. The specific anti-HDAC1 antibody and negative control IgG were used for chromatin immunoprecipitation. Genomic DNA was used as the input control. TGF, transforming growth factor; SNAI1, Snail family transcriptional repressor 1; ChIP, chromatin immunoprecipitation; HDAC, histone deacetylase; IP, immunoprecipitation; IB, immunoblotting; WCL, whole cell lysate.
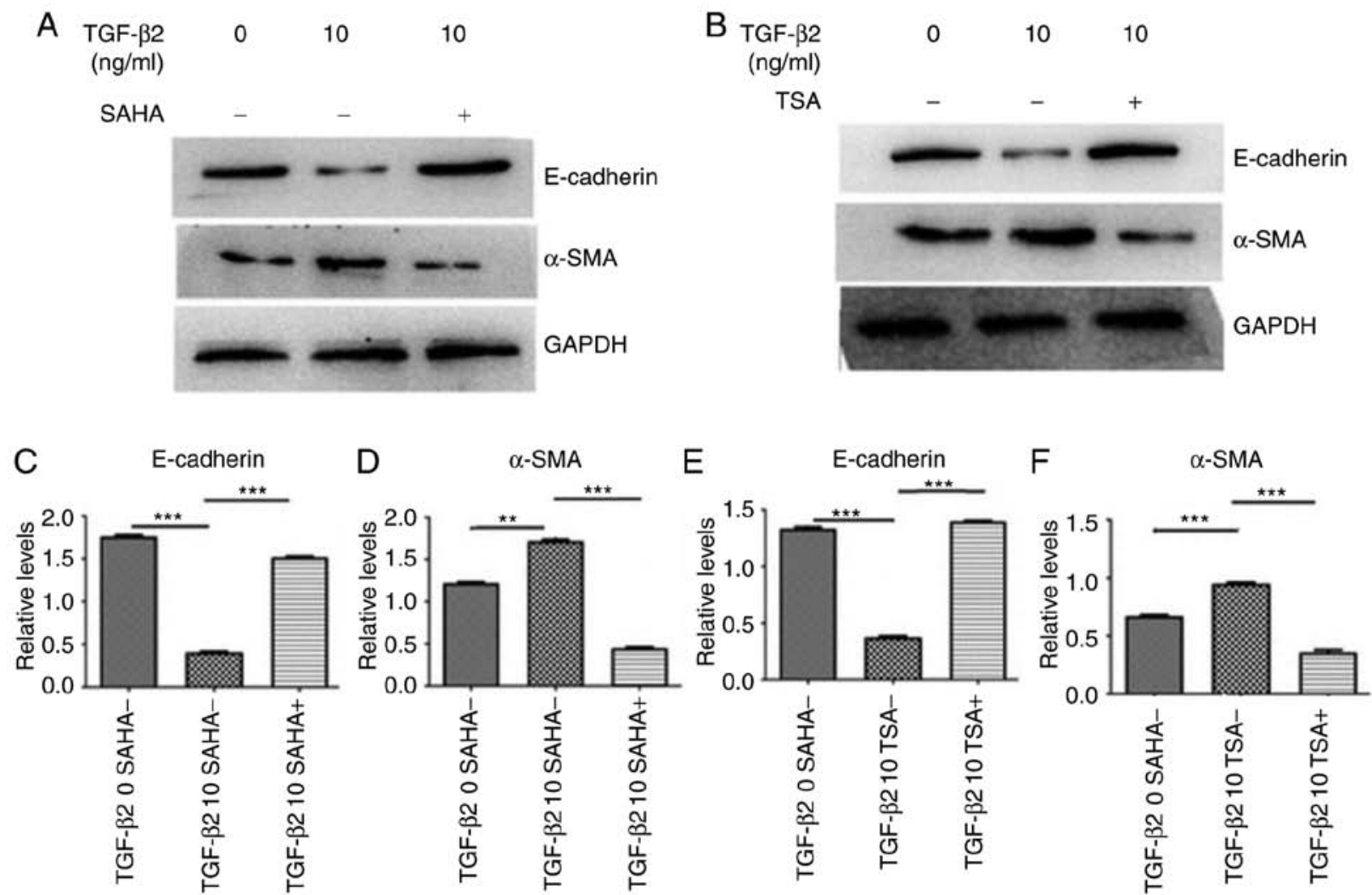

Figure 5. TSA and SAHA prevent TGF- $\beta 2$-induced EMT in HLEB-3 cells. HLEB-3 cells were exposed to TGF- $\beta 2$ with or without SAHA or TSA. Western blot analysis after (A) SAHA and (B) TSA treatment. Quantification of (C) E-cadherin and (D) $\alpha$-SMA after SAHA treatment. Quantification of (E) E-cadherin and (F) $\alpha$-SMA after TSA treatment. $\mathrm{n}=3 .{ }^{* *} \mathrm{P}<0.01,{ }^{* * * *} \mathrm{P}<0.001$. TGF, transforming growth factor; SNAI1, Snail family transcriptional repressor 1 ; TSA, trichostatin A; SAHA, suberoylanilide hydroxamic acid. 
Collectively, the present study suggested that SNAI1 interacted with HDAC1 to control TGF- $\beta 2$-induced EMT in cultured HLECs. Therefore, HDAC inhibitors may be a potential method for the treatment of PCO.

\section{Acknowledgements}

The authors would like to thank Professor Yi Lv, the head of the National Local Joint Engineering Research Center for Precision Surgery \& Regenerative Medicine and Shaanxi Province Center for Regenerative Medicine and Surgery Engineering Research for sharing experimental facilities.

\section{Funding}

The present study was supported by the NSFC (grant no. 81470614), Shaanxi Young Talent Scholar Grant (grant no. 2016KJXX-12) and a research grant from First Affiliated Hospital of Xi'an Jiaotong University (grant no. 2015YK25).

\section{Availability of data and materials}

The datasets used and/or analyzed during the present study are available from the corresponding author on reasonable request.

\section{Authors' contributions}

NG, JL, YW, QK and CP designed experiments. NG, YQ and YW performed the experiments. NG, JL, YW, QK and CP analyzed and interpreted the data. NG, JL, YW, QK and CP wrote and revised the manuscript. All the authors approved the final version.

\section{Ethics approval and consent to participate}

Not applicable.

\section{Patient consent for publication}

Not applicable.

\section{Competing interests}

The authors declare that they have no competing interests.

\section{References}

1. Awasthi N, Guo S and Wagner BJ: Posterior capsular opacification: A problem reduced but not yet eradicated. Arch Ophthalmol 127: 555-562, 2009.

2. Apple DJ, Escobar-Gomez M, Zaugg B, Kleinmann G and Borkenstein AF: Modern cataract surgery: Unfinished business and unanswered questions. Surv Ophthalmol 56 (6 Suppl): S3-S53, 2011.

3. Yang Y, Ye Y, Lin X, Wu K and Yu M: Inhibition of pirfenidone on TGF-beta2 induced proliferation, migration and epithlial-mesenchymal transition of human lens epithelial cells line SRA01/04 PLoS One 8: e56837, 2013.

4. de Iongh RU, Wederell E, Lovicu FJ and McAvoy JW: Transforming growth factor-beta-induced epithelial-mesenchymal transition in the lens: A model for cataract formation. Cells Tissues Organs 179: 43-55, 2005.

5. Saika S, Yamanaka O, Flanders KC, Okada Y, Miyamoto T, Sumioka T, Shirai K, Kitano A, Miyazaki K, Tanaka S and Ikeda K: Epithelial-mesenchymal transition as a therapeutic target for prevention of ocular tissue fibrosis. Endocr Metab Immune Disord Drug Targets 8: 69-76, 2008.
6. Gonzalez DM and Medici D: Signaling mechanisms of the epithelial-mesenchymal transition. Sci Signal 7: re8, 2014.

7. Garweg JG, Zandi S, Gerhardt C and Pfister IB: Isoforms of TGF- $\beta$ in the aqueous humor of patients with pseudoexfoliation syndrome and a possible association with the long-term stability of the capsular bag after cataract surgery. Graefes Arch Clin Exp Ophthalmol 255: 1763-1769, 2017.

8. Liu B, Gao J, Lyu BC, Du SS, Pei C, Zhu ZQ and Ma B: Expressions of TGF- $\beta 2$, bFGF and ICAM- 1 in lens epithelial cells of complicated cataract with silicone oil tamponade. Int J Ophthalmol 10: 1034-1039, 2017.

9. Pei C, Ma B, Kang QY, Qin L and Cui LJ: Effects of transforming growth factor $\beta 2$ and connective tissue growth factor on induction of epithelial mesenchymal transition and extracellular matrix synthesis in human lens epithelial cells. Int J Ophthalmol 6: 752-757, 2013.

10. Ma B, Kang Q, Qin L, Cui L and Pei C: TGF- $\beta 2$ induces transdifferentiation and fibrosis in human lens epithelial cells via regulating gremlin and CTGF. Biochem Biophys Res Commun 447: 689-695, 2014.

11. Yamada N, Sugai T, Eizuka M, Tsuchida K, Sugimoto R, Mue Y, Suzuki M, Osakabe M, Uesugi N, Ishida K, et al: Tumor budding at the invasive front of colorectal cancer may not be associated with the epithelial-mesenchymal transition. Hum Pathol 60: 151-159, 2017.

12. Matsuno Y, Coelho AL, Jarai G, Westwick J and Hogaboam CM: Notch signaling mediates TGF- $\beta 1$-induced epithelial-mesenchymal transition through the induction of Snail. Int J Biochem Cell Biol 44: 776-789, 2012.

13. Nieto MA: The snail superfamily of zinc-finger transcription factors. Nat Rev Mol Cell Biol 3: 155-166, 2002.

14. Lin Y, Dong C and Zhou BP: Epigenetic regulation of EMT: The Snail story. Curr Pharm Des 20: 1698-1705, 2014.

15. Imai S, Armstrong CM, Kaeberlein $M$ and Guarente L: Transcriptional silencing and longevity protein Sir2 is an NAD-dependent histone deacetylase. Nature 403: 795-800, 2000.

16. Livak KJ and Schmittgen TD: Analysis of relative gene expression data using real-time quantitative PCR and the 2(-Delta Delta C(T)) method. Methods 25: 402-408, 2001.

17. Wang Y, Shi J, Chai K, Ying X and Zhou BP: The Role of Snail in EMT and Tumorigenesis. Curr Cancer Drug Targets 13: 963-972, 2013.

18. Dewey S: Posterior capsule opacification. Curr Opin Ophthalmol 17: 45-53, 2006

19. Wang YN, Qin L, Li JM, Chen L and Pei C: Expression of transcription factors Slug in the lens epithelial cells undergoing epithelial-mesenchymal transition induced by connective tissue growth factor. Int J Ophthalmol 8: 872-876, 2015.

20. Liu J, Xu D, Li J, Gao N, Liao C, Jing R, Wu B, Ma B, Shao Y and Pei C: The role of focal adhesion kinase in transforming growth factor- $\beta 2$ induced migration of human lens epithelial cells. Int J Mol Med 42: 3591-3601, 2018.

21. Li J, Tripathi BJ and Tripathi RC: Modulation of pre-mRNA splicing and protein production of fibronectin by TGF-beta 2 in porcine trabecular cells. Invest Ophthalmol Vis Sci 41: 3437-3443, 2000.

22. Lamouille S, Xu J and Derynck R: Molecular mechanisms of epithelial-mesenchymal transition. Nat Rev Mol Cell Biol 15: 178-196, 2014.

23. Tamiya S, Liu L and Kaplan HJ: Epithelial-mesenchymal transition and proliferation of retinal pigment epithelial cells initiated upon loss of cell-cell contact. Invest Ophthalmol Vis Sci 51: 2755-2763, 2010.

24. Dwivedi DJ, Pino G, Banh A, Nathu Z, Howchin D, Margetts P, Sivak JG and West-Mays JA: Matrix metalloproteinase inhibitors suppress transforming growth factor-beta-induced subcapsular cataract formation. Am J Pathol 168: 69-79, 2006.

25. Hales AM, Chamberlain CG, Dreher B and McAvoy JW: Intravitreal injection of TGFbeta induces cataract in rats. Invest Ophthalmol Vis Sci 40: 3231-3236, 1999.

26. Maring JA, van Meeteren LA, Goumans MJ and Ten Dijke P: Interrogating TGF- $\beta$ function and regulation in endothelial cells. Methods Mol Biol 1344: 193-203, 2016.

27. Conway J, Al-Zahrani KN, Pryce BR, Abou-Hamad J and Sabourin LA: Transforming growth factor $\beta$-induced epithelial to mesenchymal transition requires the Ste20-like kinase SLK independently of its catalytic activity. Oncotarget 8: 98745-98756, 2017.

28. Matheus LHG, Simao GM, Amaral TA, Brito RBO, Malta CS, Matos YST, Santana AC, Rodrigues GGC, Albejante MC, Bach EE, et al: Indoleamine 2,3-dioxygenase (IDO) increases during renal fibrogenesis and its inhibition potentiates TGF- $\beta$ 1-induced epithelial to mesenchymal transition. BMC Nephrol 18: 287, 2017. 
29. Yang L, Xing S, Wang K, Yi H and Du B: Paeonol attenuates aging MRC-5 cells and inhibits epithelial-mesenchymal transition of premalignant $\mathrm{HaCaT}$ cells induced by aging MRC-5 cell-conditioned medium. Mol Cell Biochem 439: 117-129, 2018.

30. Guo R, Meng Q, Guo H, Xiao L, Yang X, Cui Y and Huang Y: TGF- $\beta 2$ induces epithelial-mesenchymal transition in cultured human lens epithelial cells through activation of the $\mathrm{PI} 3 \mathrm{~K} / \mathrm{Akt} / \mathrm{mTOR}$ signaling pathway. Mol Med Rep 13: 1105-1110, 2016.

31. Vinnakota JM and Gummadi SN: Snail represses the expression of human phospholipid scramblase 4 gene. Gene 591: 433-441, 2016.

32. Medici D, Potenta S and Kalluri R: Transforming growth factor- $\beta 2$ promotes Snail-mediated endothelial-mesenchymal transition through convergence of Smad-dependent and Smad-independent signalling. Biochem J 437: 515-520, 2011.

33. Takahashi M, Akamatsu H, Yagami A, Hasegawa S, Ohgo S, Abe M, Iwata $Y$, Arima M, Mizutani H, Nakata S and Matsunaga K: Epithelial-mesenchymal transition of the eccrine glands is involved in skin fibrosis in morphea. J Dermatol 40: 720-725, 2013

34. Yu W, Ruest LB and Svoboda KK: Regulation of epithelial-mesenchymal transition in palatal fusion. Exp Biol Med (Maywood) 234: 483-491, 2009.

35. Biswas $\mathrm{H}$ and Longmore GD: Action of SNAIL1 in cardiac myofibroblasts is important for cardiac fibrosis following hypoxic injury. PLoS One 11: e0162636, 2016.

36. Zhang L, Li Z, He W, Xu L, Wang J, Shi J and Sheng M: Effects of astragaloside IV against the TGF- $\beta 1$-induced epithelial-to-mesenchymal transition in peritoneal mesothelial cells by promoting Smad 7 expression. Cell Physiol Biochem 37: 43-54, 2015.

37. Batlle E, Sancho E, Franci C, Domínguez D, Monfar M, Baulida J and García De Herreros A: The transcription factor snail is a repressor of E-cadherin gene expression in epithelial tumour cells. Nat Cell Biol 2: 84-89, 2000.

38. de Ruijter AJ, van Gennip AH, Caron HN, Kemp S and van Kuilenburg AB: Histone deacetylases (HDACs): Characterization of the classical HDAC family. Biochem J 370 737-749, 2003.

39. Zupkovitz G, Tischler J, Posch M, Sadzak I, Ramsauer K, Egger G, Grausenburger R, Schweifer N, Chiocca S, Decker T and Seiser C: Negative and positive regulation of gene expression by mouse histone deacetylase 1. Mol Cell Biol 26: 7913-7928, 2006.
40. Ferrari-Amorotti G, Chiodoni C, Shen F, Cattelani S, Soliera AR, Manzotti G, Grisendi G, Dominici M, Rivasi F, Colombo MP, et al: Suppression of invasion and metastasis of triple-negative breast cancer lines by pharmacological or genetic inhibition of slug activity. Neoplasia 16: 1047-1058, 2014.

41. von Burstin J, Eser S, Paul MC, Seidler B, Brandl M, Messer M, von Werder A, Schmidt A, Mages J, Pagel P, et al: E-cadherin regulates metastasis of pancreatic cancer in vivo and is suppressed by a SNAIL/HDAC1/HDAC2 repressor complex. Gastroenterology 137: 361-371, 371.e1-e5, 2009.

42. Liu YW, Sun M, Xia R, Zhang EB, Liu XH, Zhang ZH, $\mathrm{Xu}$ TP, De W, Liu BR and Wang ZX: LincHOTAIR epigenetically silences miR34a by binding to PRC2 to promote the epithelial-to-mesenchymal transition in human gastric cancer. Cell Death Dis 6: e1802, 2015.

43. Liu S, Ye D, Guo W, Yu W, He Y, Hu J, Wang Y, Zhang L, Liao Y, Song H, et al: G9a is essential for EMT-mediated metastasis and maintenance of cancer stem cell-like characters in head and neck squamous cell carcinoma. Oncotarget 6: 6887-6901, 2015.

44. Ziemka-Nalecz M, Jaworska J, Sypecka J and Zalewska T: Histone deacetylase inhibitors: A therapeutic key in neurological disorders? J Neuropathol Exp Neurol 77: 855-870, 2018.

45. Hahnen E, Hauke J, Trankle C, Eyupoglu IY, Wirth B and Blumcke I: Histone deacetylase inhibitors: Possible implications for neurodegenerative disorders. Expert Opin Investig Drugs 17: 169-184, 2008

46. Mwakwari SC, Patil V, Guerrant W and Oyelere AK: Macrocyclic histone deacetylase inhibitors. Curr Top Med Chem 10: 1423-1440, 2010

47. Duvic M, Talpur R, Ni X, Zhang C, Hazarika P, Kelly C, Chiao JH, Reilly JF, Ricker JL, Richon VM and Frankel SR: Phase 2 trial of oral vorinostat (suberoylanilide hydroxamic acid, SAHA) for refractory cutaneous T-cell lymphoma (CTCL). Blood 109: 31-39, 2007.

48. Piekarz RL, Frye R, Turner M, Wright JJ, Allen SL, Kirschbaum MH,Zain J, Prince HM, Leonard JP, Geskin LJ, et al: Phase II multi-institutional trial of the histone deacetylase inhibitor romidepsin as monotherapy for patients with cutaneous T-cell lymphoma. J Clin Oncol 27: 5410-5417, 2009.

49. Patil V, Sodji QH, Kornacki JR, Mrksich M and Oyelere AK: 3-Hydroxypyridin-2-thione as novel zinc binding group for selective histone deacetylase inhibition. J Med Chem 56: 3492-3506, 2013 